\title{
THE HORIZONS OF KNOWLEDGE AND THE POWER OF SYNTHESIS
}

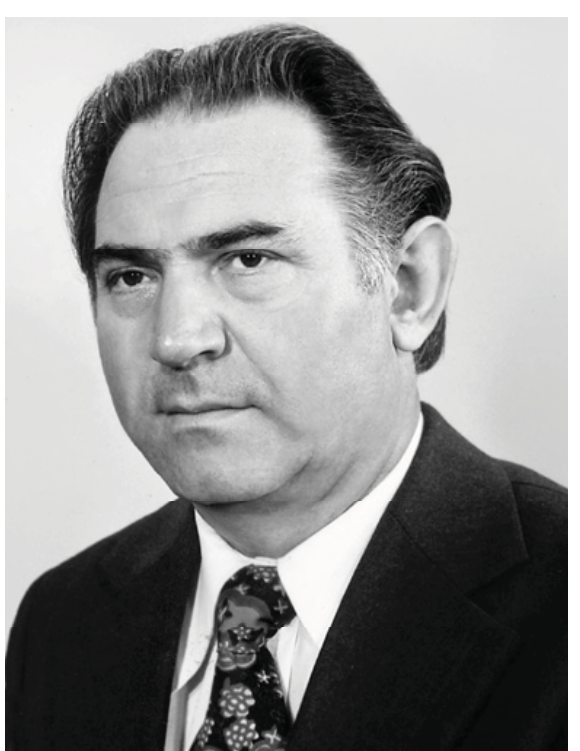

The father of Russian science, Mihailo Lomonosov, in one of his most beautiful works, "Words on the Use of Chemistry" - an embodiment of his philosophy of life and work - wrote that: "Science discovers and and explains the hidden features of things, as well as the hidden reasons for their inner function; in its turn invention facilitates a better use of science in man's life...”. In modern terms, Lomonosov's assertion can be interpreted somewhat like this: Discovery is the supreme form of scientific creation, but inventions that are formally legitimized with legal patents are mainly the result of the creative synthesis in daily life. The ratio between discoveries and inventions is one to several thousands. It can be said that one of our greatest discoverers, the famous Isaac Bersuker - an outstanding scholar, and the founder of the internationally known School of Quantum Chemistry and Chemical Physics of the Republic of Moldova - is a giant of thought.

Born on the 12th of February 1928 to the family of a Chishinau carpenter named Boruh, he together with his father dreamed of becoming a first-rate locksmith, but his destiny was another - he chose to unlock the subtleties of electrons and atomic nucleus "respiration”, which could be explained only by his discovery of the pulsating movement of molecules.

After graduating from the Faculty of Physics and Mathematics at The State University of Moldova in 1952, he wrote a PhD thesis on the topic, "Optical transitions in atoms and molecules with a polarizable structure” (Saint Peterburg, 1957). His second thesis for the title of Doctor Habilitat in physical-mathematical sciences, was titled, "Contributions in the field of quantum theory of transitional metal complexes" (the same place, 1964). He became a University Professor (1967), a corresponding member (1972), a full member (academician) of the Academy of Sciences of Moldova (A.S.M.) (1989). Subsequently he became a member of the Chemical Society of the United States.

He was the first from the Institute of Chemistry of A.S.M. to organize a laboratory for the study of Quantum Chemistry (1964), which, along with careful research allowed him to register his first discovery, number 202 (1978). Thus, he became the first laureate of the State Prize of the Republic of Moldova in the field of science and technology (1979).

The fruitful development of quantum chemistry - a composite discipline, being at the interface between physics and chemistry - led to explanation of some fundamental questions of chemistry such as the nature of chemical bonds and the relationship between molecular structure and physical-chemical properties, which may also explain how to build biologically active compounds with programmable proprieties. The contributions of the Bersukerian School have been important for promoting research in the field of integrated chemistry by using fundamental principles and equations of quantum mechanics to reveal the difficult problems regarding the reactivity of chemical bonds, electronic structure of reactant molecules, as well as the transition state in catalysis, the modeling of molecular systems containing transitional metals, and the regulation of processes specific to life. The scholar introduced and developed the concept of vibronic interactions applicable in chemistry, biology and physics and developed the vibronic theory of seignetto-electricity, which allows prediction and discovery of new phenomena. Professor Isaac Bersuker has published over 600 scientific works, including 13 widespread monographs (6 in Russian and 7 in English). He has been scientific advisor to 50 doctors and 10 habilitate doctors in science.

All these accomplishments have been the result of hard work and perspiration, common to minds, inspired by the demon of creation and discovery. Maybe the most subtle and surprising description of the exceptional mind and nature of Isaac Bersuker was written by Victor Polingher, one of his disciples, in his work, "The Chemist”, written in January 1988, (during the "Perestroika" period, when things began to have names.): "His cheerful disposition and constant optimism helped him face many hardships in his difficult work as a theoretical scholar. Frankly speaking, we have to mention that public scientific opinion was initially critical of almost all that Isaac Bersuker had published. Thus, the vibronic theory of seignetto-electricity - which today is recognized and appreciated - needed almost 20 years before being accepted by the scientific community. Some of his research results still provoke great debates even today. In paraphrasing a well-known poem it could be said: “... how many roads I've taken and how few mistakes I've made”.

Isaac Bersuker is a man who is not too flattered by complements. At the same time he is a man who understands and does not hesitate to consider real and honest work on an idea proposed by his close or occasional colleagues. So, looking through my modest contributions in newspapers and specialized reviews, especially those in which I'm trying 
to reconstruct the inner life of our academic and university life, the tireless Isaac Bersuker sends me a letter full of optimism even from the University of Texas, in which he encourages me by saying: “My dear colleague, you've taken a very noble task of "chronicling” the great achievements from the Academy of Sciences and the scientific community of Moldova. I think that not only the present generation, but also the future one will be very grateful for this work. Persevere, even if you meet with difficulties and impediments”.

A more detailed analysis of, Isaak. Bersukers’ personality would require more space, while our goal is to emphasize the most important contributions of his life and work. We met at the Institute of Chemistry of A.S.M. the same day as its inauguration (April 1959): I came from the Tiraspol University of Pedagogy where I was holding Chemistry lectures. He came from the Balti University of Pedagogy where he was a physics lecturer. I - doctor in Chemistry, and he - doctor in physics-mathematics; both were members of the first scientific Council of April 1959. In 1961 we both received apartments on the same floor and in the same building at 63 Gheorghe Asachi Street. We both held the position of deputy director for scientific work, and we both settled new laboratories - he of quantum chemistry, I of bioinorganic chemistry. We both were favored with a happy destiny shaped by our spiritual father, the late Antonie Ablov, a destiny that perpetuates the tradition. So, I consider myself qualified to confirm the remarkable spirit of this brilliant expert in the modern concepts of physics and chemistry, Isaac Bersuker. My collaboration and communication with him have always been a real delight.

The laboratory of Quantum Chemistry at the Institute of Chemistry of A.S.M. in its first years succeeded in transforming itself into a "pearl of the Soviet Union” (Mihail Veselov), recognized later all over the world. Specialists from the four corners of the world came to him either to recognize the laboratory's achievements, to participate in the many conferences and symposia focused on the laboratory's area of research, or for long-term training. A professor from Marburg University, D. Reinen, who participated in the 10th International Symposium dedicated to the Jahn-Teller effect (Chisinau, 26-29 September 1989), wrote in a news article that he greatly appreciated the high standards of scientific research by the scientists from Chisinau and that "the research group of Isaac Bersuker, the academician of the Academy of Sciences of Moldova, approaches international standards. This is due to the fact that professor Bersuker and his disciples maintain outstanding cooperation with scientific centers from abroad. In science it is impossible to compete with others when one is isolated".

Academician Isaac Bersuker understood this truth very well. Thus he entered into an employment contract with the University of Texas, at Austin, where for two and half years he worked intensively on developing and improving a method of modeling molecular systems containing transitional metals. To get a sense of the conditions and intellectual forces of this institution it should be mentioned that the University of Texas houses two Nobel Prize laureates, 50, 000 students and 10, 000 doctoral candidates. As a result of his diligent research it is possible to regulate metal-containing biological systems. These include hemoglobin, vitamin B12, cytochrome, peroxydase, as well as other forms of medicine These results can be used in biology and medical biology, for the development of new medicines.

Isaac Bersuker together with his closest collaborators - including seven Doctors Habilitat. Moisei Belinski, Serghei Borsci, Anatol Dimoglo, Mihail Kaplan, Victor Polingher, Boris Tukerblat, Beniamin Vehter, became involved in the universal science, which attracted them to the most famous scientific centers from Belgium, France, Israel, Italy, Spain, the U.S.A., Turkey, and other countries.

My friend, Professor Isaac Bersuker tohether with his lovely wife, Lilia, his talented son, Ghenadie and two admirable grandsons has settled in Austin, Texas. The scholar himself has declared that this place is not a permanent home, but an extended scientific journey that has lasted more than 10 years so far. Isaac Bersuker carries on his activity at the University of Texas, where he has all the necessary facilities for his fundamental research and where his creative work is highly appreciated. From the beginning of the 1990's the American Biographical Institute included him in the group of the 500 international scientific leaders, assigning to him the title of the world's most imposing and honored scholar of the 9th decade. In 1992 the International Biographical Centre from Cambridge, England conferred on him the title of "The Man of The Year".

As an ambassador during the difficult times when the fate of science in Moldova was at stake, he responded promptly with useful suggestions for "The Concept of Reformation of the Research-Development Sphere of the Republic of Moldova," which has now been accepted by the parliament. As always, he knew how to explain things and to contribute to the cessation of the process of ruining the fundaments of our academic scientific research. During his stay Chisinau in July 2002, in a relevant interview given on 29 August 2002 ("Kishinevskii obozrevateli”, he tried to explain the difficult situation faced by our academic science and proposed some solutions which would allow us to overcome the critical situation, making some surprising remarks that we might take seriously::«In destroying science we sentence ourselves to poverty....In the Republic of Moldova serious mistakes against science have been committed. We need decades to correct them. The old mentality of the national leadership did not permit solving this problem at the proper time, as it was occurring throughout the world. Elsewhere money is granted for the development of science, while in our country money is granted for wages”. Isaac Bersuker pays a great deal of attention to the support that the state gives for scientific development. Only through active cooperation between the authorities and the fundamental research 
process can we move science toward an acceptable level of performance. How can the fair-minded ideas of this famous architect of science be ignored?

Lately Isaac Bersuker has focused his knowledge meticulously accumulated during the last half century on the most important problem of the present times - Ecotoxicology. Thisis the right time and the right place for this initiative . At present the scholar has been invited to participate in the highest international forums focused on ecological issues. At the 2nd International Conference of Ecologic Chemistry held in Chisinau (11- 12 October 2002), Isaac Bersuker was appointed the chairman of the Scientific Committee. At the same meeting he read a highly acclaimed paper regarding the utilization of Computer Based Chemistry in testing and predicting toxicity in Industrial Ecology ( see "The Environment". 2002. N.3 (3). P. 10).

Being deeply concerned with industrial ecology, a distinct branch of ecology whose objective is to reduce emission of toxic substances in water, air and soil, Isaac Bersuker proposes to use the so-called electrono-conformatioal, computerbased method to identify pharmacophores and predict bioactivity in pharmaceutics. This method was developed earlier to identify toxicophores and predict their toxicity. In this case, computer-based chemistry serves to analyze data concerning the specific toxic character of different structures in industry in order to detect the toxicophore groups in these molecules, and the spatial position and electronic structure which determines their toxicity. The method is fast, cheap and efficient, ensuring a high level of prediction with $90 \%$ accuracy.

I think, as I describe, with considerable emotion, the man's life and biography, that it would be good to have as many fellow country men like Isaac Bersuker as possible,, who serve as ambassadors throughout the world to ensure permanent effective and affective contacts with the great scientific centers from abroad. Isaac Bersuker is a man and a scholar who in fact promotes the image of the Earth and of our Academy on the globe, an earth that he loves and will never leave, and an Academy that he wants to see among the modern institutions of the world. An Earth, which, bless the Lord, appreciates the scholar. In February 2004, Isaac Bersuker was favored with the “Order of Honor” of the Republic, as a sign of great appreciation for his outstanding contribution to the development of academic relations between the Republic of Moldova and the United States of America.

Today as never before, we have a real need for such great messengers and promoters as Isaac Bersuker.

Dumitru BATÎR

Dr. hab. in chemistry, University professor State Prize Laureate 